\title{
RIP CURRENT OBSERVATION WITH X-BAND RADAR
}

\author{
Satoshi Takewaka ${ }^{1}$ and Taishi Yamakawa ${ }^{2}$
}

\begin{abstract}
X-band radar measurements were conducted at the research pier HORS, of the Port and Airport Research Institute, located in Hasaki, Japan. Ensembles of original radar images over 17 minutes were processed to time-averaged radar images every hour, which were analyzed to estimate the intertidal morphology and occurrence of rip currents. Several streaks extending in the cross shore direction appear in the averaged images which resemble to a neck and head of a rip current captured often in aerial photos or video imageries. The natures of these characteristic patterns in the timeaveraged image are investigated through comparisons between optical images, floater release experiment and statistic analyses on sea conditions.
\end{abstract}

Keywords: rip current; field observation; X-band radar; occurrence of rip current

\section{Introduction}

Rip currents are narrow and transient seaward flows extending over the breaker zone. They play important roles in offshore sediment transport, shoreline and bar system evolutions and beach safety. Rip current observation with instruments requires extensive efforts, since it is unsteady and sometimes migrates rapidly in the longshore. Remote sensing using X-band radar, providing both spatial and temporal data, has the potential to observe the entire rip current system and is examined here in this work.

\section{$\mathrm{X}$-band radar observation}

X-band radar measurements were conducted at the research pier HORS, of the Port and Airport Research Institute, located in Hasaki, Japan, facing the Pacific Ocean. The main facilities are a 400meter pier on an almost straight sandy coast and a research building on the backshore, which is located approximately $100 \mathrm{~m}$ backwards from the mean shoreline position. The radar was installed on the roof of the research building at a height of approximately $17 \mathrm{~m}$ from the mean sea level (Takewaka 2005).
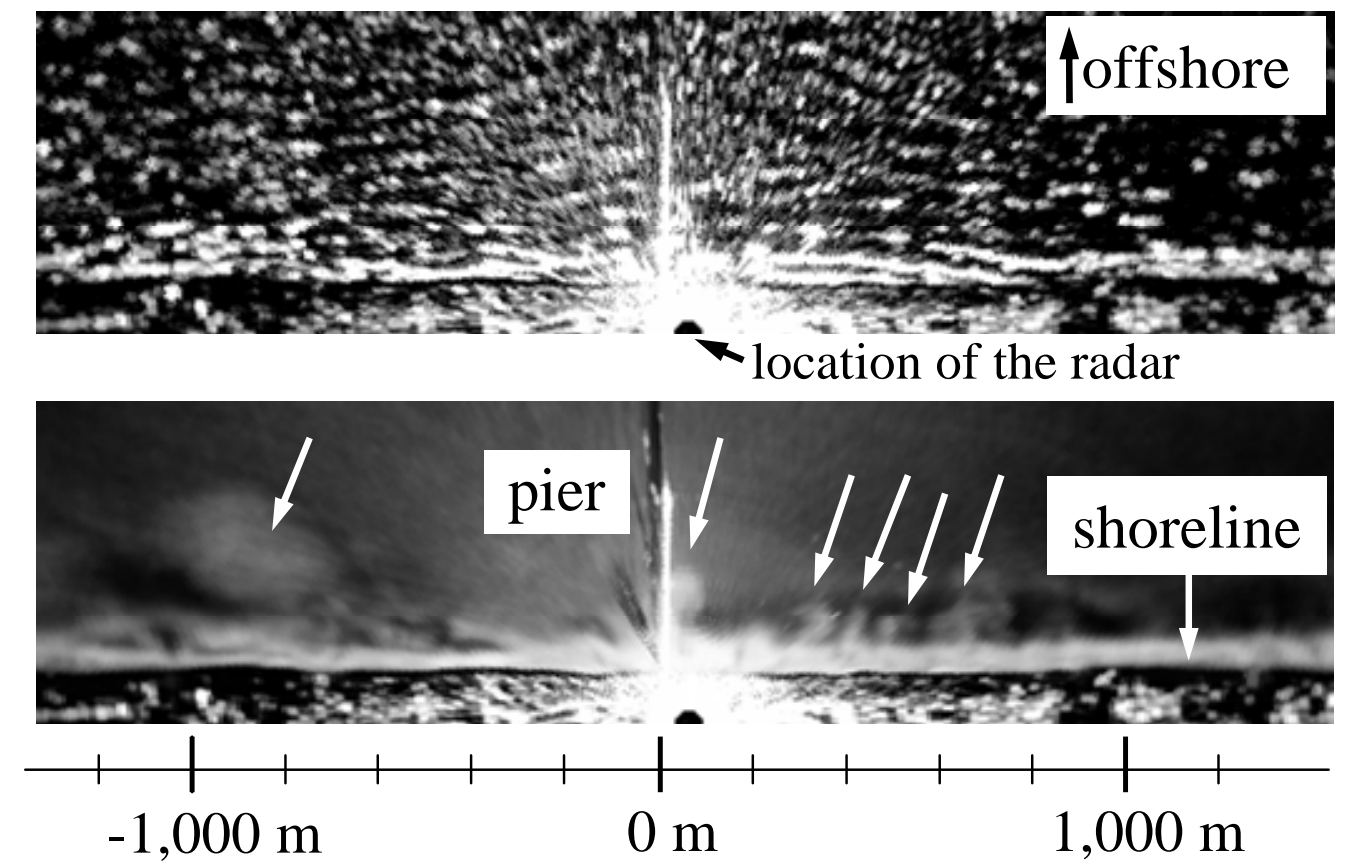

Figure 1 Original radar image (upper panel) and time-averaged radar image (2008 Jan 15, 16 JST). Oblique arrows in the lower panel indicate streaks extending in the cross shore.

\footnotetext{
${ }^{1}$ Department of Engineering Mechanics and Energy, University of Tsukuba, Tsukuba, 305-8573, Japan

${ }^{2}$ Tokyo Power Electric Company, Japan
} 

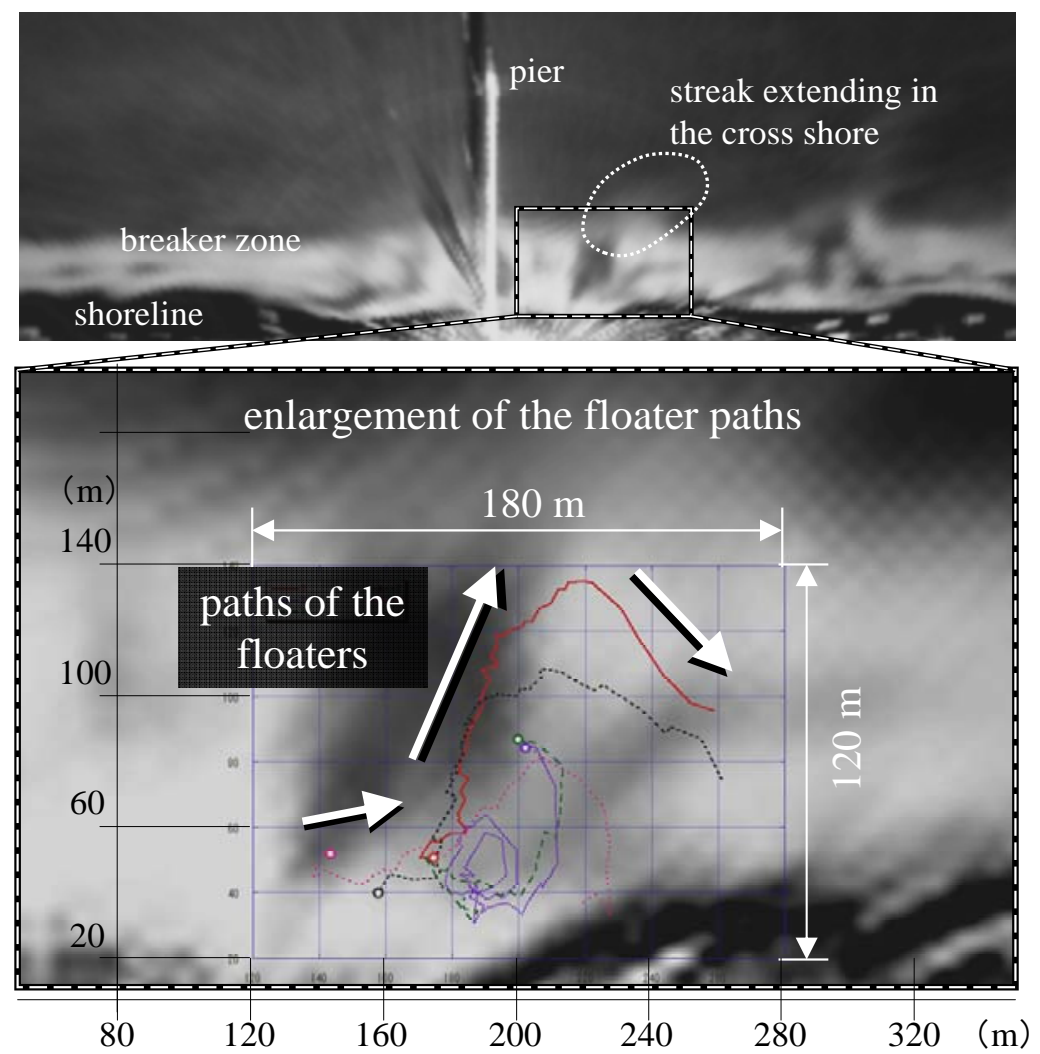

Figure 2 Paths of the floaters overlapped on time-averaged radar image (2007 July 31, 15h)

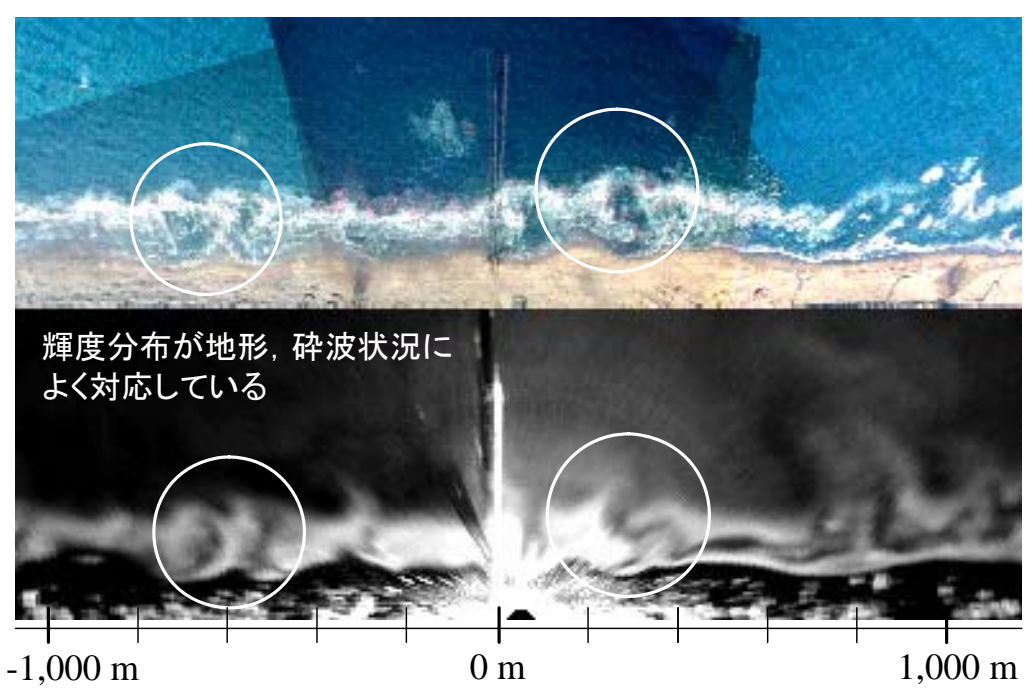

Figure 3 Time-averaged radar image and aerial photograph (2007 April 12, 15h)

X-band radar is an imaging device that provides instantaneous distributions of wave crests and shorelines. Ensembles of original radar images over 17 minutes were processed to time-averaged radar images every hour, which were analyzed to estimate the intertidal morphology and occurrence of rip currents. This system is used for longshore observations of intertidal bathymetry (Takewaka 2005), mega-cusp migrations (Elsayed and Takewaka 2008), wave propagation (Hasan and Takewaka 2007) and wave run-up (Hasan and Takewaka 2009) at stormy condition. 


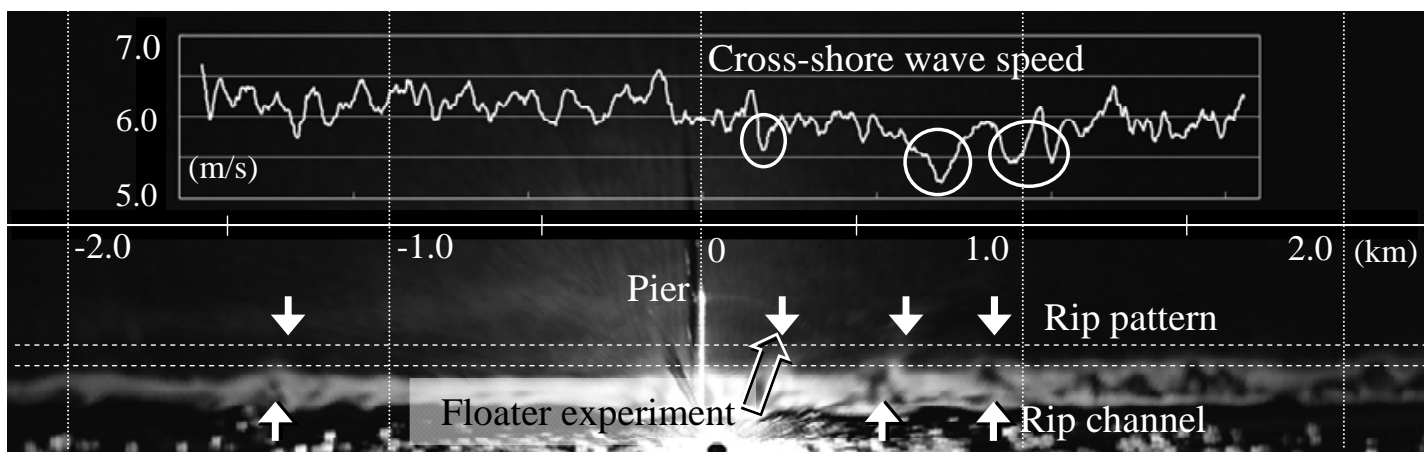

Figure 4 Longshore distribution of cross-shore component of the wave speeds (upper panel) with the averaged image (2007 July 31, 15h). Enclosed locations indicate slower wave speeds which lie in the seawards of rip patterns.

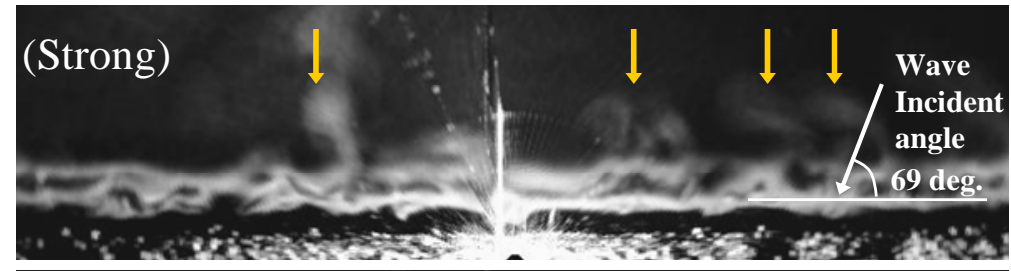
2005 Nov 03, 22h JST
Wave height: $0.99 \mathrm{~m}$
Wave period: $8.9 \mathrm{~s}$
Wave incident angle: $69 \mathrm{deg}$.
Tide level: $-0.13 \mathrm{~m}$

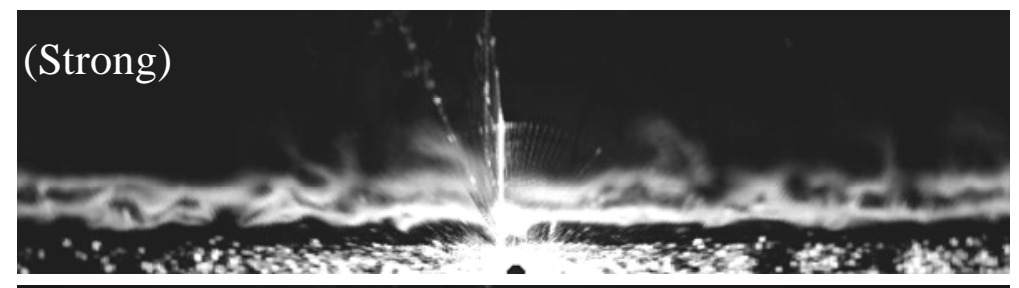

2005 Nov 04, 00h JST

Wave height: $0.93 \mathrm{~m}$

Wave period: $8.5 \mathrm{~s}$

Wave incident angle: 66 deg.

Tide level: $-0.08 \mathrm{~m}$

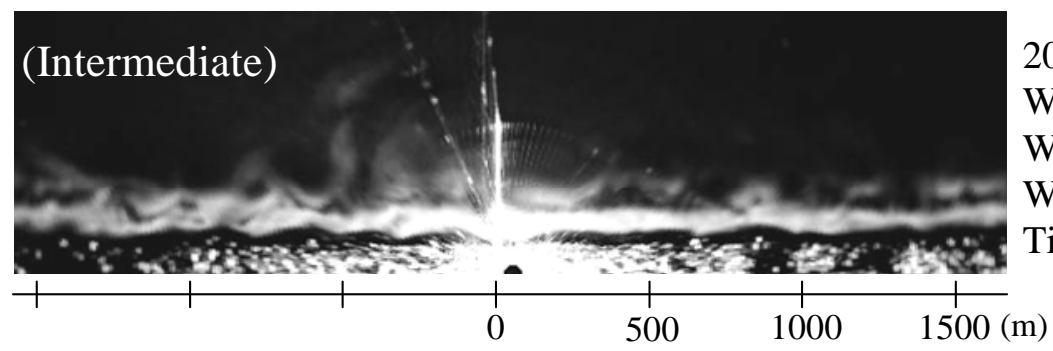

2005 Nov 04, 02h JST

Wave height: $0.82 \mathrm{~m}$

Wave period: $8.2 \mathrm{~s}$

Wave incident angle: 63 deg.

Tide level: $0.41 \mathrm{~m}$

Figure 5 Transition of rip current patterns and their identified intensities.

Figure 1 shows an example of original image and averaged image. Individual waves in the original image vanish in the time-averaged image. A horizontal and bright edge extending in the longshore corresponds to the shoreline. There are several streaks extending in the cross shore direction which resemble to a neck and head of a rip current captured often in aerial photos or video imageries. The natures of these characteristic patterns in the time-averaged image are investigated in the followings.

\section{Field experiment}

GPS-equipped floaters were released from the swash zone simultaneously with the radar observation to compare the current pattern and locations of the rip head-like patterns observed in the averaged images. Figure 2 shows the paths of the floaters overlapped on the time-averaged image. There was a circulation cell extending approximately $100 \mathrm{~m}$ offshore-wards. Floaters travelled with a speed of $0.5 \mathrm{~m} / \mathrm{s}$ on the rip flow. A streak in the radar image appears at the same location where floaters drifted to the off-shore, suggesting the streak is corresponding to a rip current. Brighter parts in the averaged image have stronger backscatter from the sea surface, which might be induced from the foams transported by the rip current. 
Table 1 Rip intensities and sea condition

\begin{tabular}{c|c|c|c|c}
\hline $\begin{array}{c}\text { Rip intensity rank } \\
\text { (Intensity range) }\end{array}$ & $\begin{array}{c}\text { Weak } \\
(\sim 199)\end{array}$ & $\begin{array}{c}\text { Intermediate } \\
(200 \sim 399)\end{array}$ & $\begin{array}{c}\text { Strong } \\
(400 \sim)\end{array}$ & 1,001 \\
\hline Number of images & 1,304 & 1,310 & 8.2 & 8.15 \\
\hline Mean wave period [s] & 8.4 & 7.8 & 1.36 & $82-98$ \\
\hline Mean wave height [m] & 0.84 & $80-100$ & 0.60 & $80-100$ \\
\hline Wave incident angle [deg.] & $79-101$ & 0.69 & 0.68 \\
\hline
\end{tabular}

\section{Comparison between averaged radar image and aerial image}

Figure 3 shows a comparison between averaged radar image and aerial photograph taken at the same period. The aerial photograph is a snapshot, however, it depicts the breaking and non-breaking zone along the shore showing that there are similar patterns captured in both measurements. The display shows that the pattern captured in the averaged image corresponds to breaking and nonbreaking regions.

\section{Wave celerity at the rip patterns}

Travelling speeds of wave crests in the cross-shore at the rip patterns were analyzed to explore the longshore distribution of the wave celerities over the rip patterns. Analyses on sequences of original images with PIV-like technique provide cross-shore components of wave speeds. At the rip-heads, waves encounter offshore-directed current and may have smaller travelling speeds compared to the surroundings. Figure 4 shows the longshore distribution of cross-shore wave speeds with the rip positions identified from the averaged image. Wave travelling speeds in the cross-shore were approximately $0.5 \mathrm{~m} / \mathrm{s}$ smaller at the rip patterns compared to the surroundings, which might be induced from the off-shore directed flow. This magnitude of retardation is same to the offshore-wards drift speed of the floaters observed in the field experiment.

\section{Statistics on rip current occurrence}

Temporal variation of intensities of the streaks extending in the cross-shore was identified and compared with sea conditions: wave height, period and incident angle and tide level. The intensities of the streaks were estimated by image analyses evaluating longshore pixel brightness distribution. It is widely accepted that rip currents are frequently observed when the waves are close to shore normal incident, and some literature points out the dependency on tide levels.

Figure 5 shows an example of variation of the rip patterns with identified rip intensities, which indicates the rip patterns vary rapidly in a short time with the sea conditions. Table 1 shows the identified rip intensity ranks and corresponding sea conditions from the result of analysis on 3,615 images. Prominent rip current patterns are observed at this site when the incident waves are close to shore normal, and tide levels are low.

\section{ACKNOWLEDGMENTS}

The authors are grateful to Dr. Shinichi Yanagishima and to the members of the Littoral Drift Division, PAR, who provided great supports in field experiment and radar measurements.

\section{REFERENCES}

Takewaka S. 2005. Measurements of shoreline positions and intertidal foreshore slopes with X-band marine radar system, Coastal Engineering Journal, Vol.47, pp. 91-107.

Hasan J.G.M. and Takewaka S. 2007. Observation of a stormy wave field with X-band radar and its linear aspects, Coastal Engineering Journal, Vol. 49, pp. 149-171.

Elsayed G. and Takewaka S. 2008. Longshore migration of shoreline mega-cusps observed with Xband radar, Coastal Engineering Journal, Vol. 50, pp. 247-276.

Hasan J. G. M. and Takewaka S. 2009. Wave run-up analyses under dissipative condition using Xband radar, Coastal Engineering Journal, Vol. 51, pp. 177-204. 